\title{
Kulning (Swedish Cattle Calls): Acoustic, EGG, Stroboscopic and High-Speed Video Analyses of an Unusual Singing Style
}

\author{
Ahmed Geneid $^{1}$, Anne-Maria Laukkanen ${ }^{2}$, Anita McAllister ${ }^{3}$, Robert Eklund ${ }^{4}$ \\ ${ }^{1}$ Department of Otolaryngology and Phoniatrics - Head and Neck Surgery, \\ Helsinki University Hospital and University of Helsinki, Finland \\ ${ }^{2}$ Speech and Voice Research Laboratory, School of Education, University of Tampere, Finland \\ ${ }^{3}$ Division of Speech and Language pathology, Karolinska Institutet, Sweden \\ ${ }^{4}$ Department of Culture and Communication, Linköping University, Sweden \\ ahmed.geneid@hus.fi, anne-maria.laukkanen@uta.fi, \\ anita.mcallister@ki.se, robert.eklund@liu.se
}

\begin{abstract}
The Swedish cattle call singing style 'kulning' is surprisingly understudied, despite its mythical status in folklore. While some acoustic and physiological aspects have been addressed previously [1,2], a more detailed analysis is still lacking. Previous work [2] showed that sound pressure level (SPL) in kulning tapered off less than in head register as a function of distance, which warrants a study of underlying physiological mechanisms responsible for this. In the present paper, the same singer, singing the same song - in kulning and in head register ("falsetto") mode - was recorded indoors. Electroglottographic (EGG), stroboscopic, high-speed endoscopic and audio registrations were made. Analyses examined differences between kulning and head register. Results show somewhat higher SPL in kulning than in head register confirming the previous findings. EGG showed longer relative glottal closed time and higher amplitude of the signal in kulning. This suggests better vocal fold contact in kulning. Flexible nasofiberoscopy and high-speed recordings during kulning showed medial and antero-posterior narrowing of the laryngeal inlet, a clear approximation of the false vocal folds and marked adduction of the vocal folds.
\end{abstract}

Index Terms: kulning, falsetto, traditional singing styles, long-distance communication, high-speech imaging, voice production with exceptional loudness

\section{Introduction}

Throughout history, long-distance calls have been created at several different locations where there has been a need of making oneself heard over long distances. Examples include e.g. yodeling $[3,4,5]$ and whistled languages [6] and such long-distance calls have been used for both humanhuman communication and for human-animal calling.

'Kulning' is the most common term (see [7:p. 8] for an extensive listing of alternative terms) for a specific type of cattle or herding calls used mainly in the provinces Dalarna, Härjedalen and Jämtland in Sweden. Kulning is used to call cows or goats, gracing freely in the mountains, when it is time to be milked. The tradition of cattle calls dates far back in history and was most common in Dalarna, where young women looked after the live stock during summer in small mountain farms, away from the homestead. Kulning generally has no lyrics and consists of vowel-heavy syllables that feel comfortable to the singer. The singing technique is high pitched, and without vibrato to make the sound carry over long distances. Despite its well-nigh mythical status in Swedish folklore, kulning has received limited attention from a research point of view. This paper aims to remedy that situation by investigating some acoustic and physiologic properties of kulning, compared to head register singing.

\section{Previous research}

Kulning is mentioned in both [8: pp. 38 et passim] and [9], but mainly in passing. For example, Ling [9: p. 22] states that kulning is not really "singing" in a traditional sense but is more like some kind of falsetto-like calling in very high frequencies, and that it requires a tightened larynx, while Moberg [8: p. 37] points out that it is normally sung on vowels, without lyrics in the traditional sense. Johnson [1,11: pp. 216-259] reports that kulning production is characterized by a strong correlation between frequency and sound pressure level (SPL) at higher frequencies (not so much so in lower frequency ranges) and that, contrary to classical singing, the larynx moves with the frequency, and is raised considerably (up to $+39 \mathrm{~mm}$ ) when high notes are produced. Jaw opening is also correlated with high frequency (in line with classical singing). The vocal tract length is varied with up to $37 \mathrm{~mm}$, compared to $20 \mathrm{~mm}$ in (standard) singing [11: p. 245].

Previous research [11: p. 230] has shown that it was not possible to gain good optical access to the vocal folds during kulning due to the marked constriction of the epilaryngeal inlet. As has been reported, the pharynx is tightened to the point of making optical glottography impossible.

Johnson [11: pp. 228-229] reports SPL values up to $105 \mathrm{~dB}$ at 1 meter. The results presented in Johnson are largely replicated by Rosenberg [7: p. 24]. As for the acoustic properties of kulning, Uttman [12] studied spectra of kulning songs obtained from CD recordings, and reported strong partials up to the $16-18 \mathrm{kHz}$ frequency range, compared to $\sim 6 \mathrm{kHz}$ in normal folk singing.

In a free field, SPL tapers off by $6 \mathrm{~dB}$ per doubling of the distance. This figure, however, is not necessarily true in outdoor habitats where sound is reflected from the ground and vegetation and also subject to different athmospheric conditions such as wind and air humidity, In a previous study [2], we compared SPL attenuation at 1 and 11 meters, 
respectively, and found that while head register voice dropped $25.2 \mathrm{~dB}$, kulning register only dropped $9.4 \mathrm{~dB}$, thus exhibiting its remarkable resilience, SPL-wise, in its natural environment. Given the listed observations, a more fine-grained study of the physiological mechanisms that produce these differences is required, especially since the perceptual difference (from single notes) between head register and kulning is not as striking as reported physiological and acoustic differences.

\section{Data collection and method}

The singer (FP, born in 1987), the same as in our previous studies [1,2], is educated in kulning at Musikkonservatoriet in Falun and Malungs Folkhögskola, by Agneta Stolpe and AnnSofi Nilsson. Data consisted of FP singing the same cattle call (cattle call from Äppelbo in a traditional arrangement by Agneta Stolpe, Vallslinga från Äppelbo) as in our previous studies, this time in kulning mode and in head register (or falsetto) mode. The duration of the song was around one minute.

In the present study, phonation on a single pitch was studied using video-stroboscopy, high-speed endoscopy and electroglottography (EGG). According to glottal imaging, falsetto phonation is characterized by a nearly sinusoidal vocal fold movement pattern with short or even lacking glottal closure (e.g. [13]). EGG shows the vocal fold contact pattern and has been shown to differentiate between phonation type and registers [14]. To the best of our knowledge, no EGG data have been reported for kulning.

All data were collected on 14 June 2015, in an indoor location at the Helsinki University Hospital in Helsinki, Finland.

For measuring SPL, two sound-level meters were used in parallel: an Extech 407732 and a Brüel \& Kjaer 2238 Mediator. A-weighting and a slow response time (1 second) were used.

We also recorded audio, but have not used these recordings in the present study.

A dual-channel electroglottograph (Glottal Enterprises) was used to register contact area variation of the vocal folds during phonation in kulning and in head register.

Flexible fiberoscopy recordings were made using nasofiberoscope ORL Vision RS1, CCD supplied by Rehder \& Partners.

High speed recordings were carried out using KayPentax, model 9710 at 4000 frames per second. The spatial resolution of the high speed videos was $512 \times 256$ pixels. The duration of the each video taken was 4 seconds.

\section{Analysis}

\subsection{Acoustic analyses: SPL measurements}

In the present study, we measured sound pressure levels at $3 \mathrm{~cm}$ and at 1 and 11 meters from the source in one of the hospital corridors.

At $3 \mathrm{~cm}$ from the mouth, $\mathrm{dB}(\mathrm{a})$ values for head register varied between 93 and $102 \mathrm{~dB}(\mathrm{a})$, while kulning had a range between 94 and $123 \mathrm{~dB}(\mathrm{a})$, thus exhibiting higher sound values for kulning in absolute terms.

Comparing sound pressure levels at 1 and 11 meters, head register produced a level drop of around $21 \mathrm{~dB}$ (a) (from c.94 $\mathrm{dB}(\mathrm{a})$ at 1 meter, and $68-78 \mathrm{~dB}(\mathrm{a})$ at 11 meter), while kulning dropped by around $15 \mathrm{~dB}$ (from c. $97 \mathrm{~dB}(\mathrm{a})$ to $82 \mathrm{~dB}(\mathrm{a})$ ). This repeats our previous finding that kulning voice is attenuated less than head register as a function of distance, not only in its intended outdoor environment, but also in an indoor setting.

Finally, when calibrating and comparing our two sound level meters, we observed that the Extech sound-level meter in general showed $\mathrm{dB}$ values $2-3 \mathrm{~dB}$ higher than the Brüel \& Kjaer sound level meter. Although there is reason to assume that the latter is slightly more reliable, the observed variation was so big and fluctuated so much that our reported results are based on measurements from both sound-level 1 meters.

\subsection{EGG}

The principle of EGG is based on differences in the electrical conductivity between air and tissue [15]. The EGG signal is obtained by placing two (or more) electrodes on both sides of the larynx and feeding a high frequency $(>300 \mathrm{kHz})$, low voltage $(<10 \mathrm{~mA})$ alternating current between the electrodes. Variation of contact area between the vocal folds during phonation is reflected in the EGG signal. In the present study the EGG signal was analyzed for the relative contact time, CQ, as shown in Figure 1. Voce Vista software was used.

The threshold level of $25 \%$ of the peak-to-peak amplitude (seen from the impedance maximum) was chosen to represent the baseline between open and closed glottis [16] since it is problematic to locate the exact beginning and ending of the glottal opening and closing events in EGG signal. The 25\% level was chosen as it has been shown to have a good correspondence with kymographic and high speed imaging of vocal fold vibration $[17,18]$.

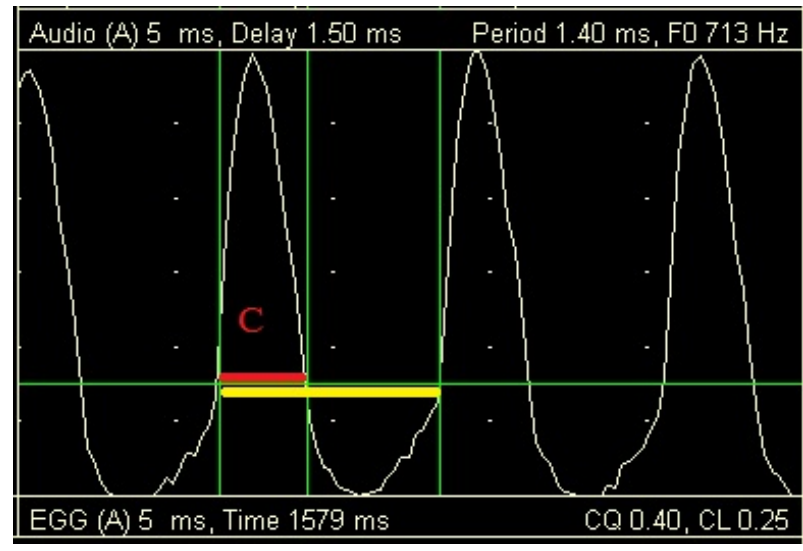

Figure 1. EGG signal (increasing impedance = decreasing contact downwards). CQ measured as closed time (red line) divided by period time (yellow line).

Table 1 below shows that CQ was higher in kulning compared to head register. F0 was also somewhat higher in kulning. Both differences were statistically significant $(p<0.001$, Wilcoxon Signed Rank $t$-test).

Table 1. Descriptive Statistics. Mean, SD and range for $C Q$ and $F 0$ results. $\mathrm{N}=$ number of periods.

\begin{tabular}{|l|c|c|c|c|c|}
\hline & $\mathrm{N}$ & Min & Max & Mean & Std. Dev. \\
\hline Kulning CQ & 493 & .40 & .55 & .4734 & .02715 \\
\hline Head Voice CQ & 493 & .26 & .57 & .4052 & .06057 \\
\hline Kulning F0 & 493 & 620.97 & 875.00 & 759.5502 & 41.87060 \\
\hline Head Voice F0 & 493 & 641.67 & 802.08 & 693.7666 & 17.81907 \\
\hline Valid N (listwise) & 493 & & & & \\
\hline
\end{tabular}


The EGG waveform differences between kulning and head voice are illustrated in Figure 2. The waveform is more rounded/less angular-looking in head voice and the signal SPL was also in many attempts somewhat smaller than in kulning.
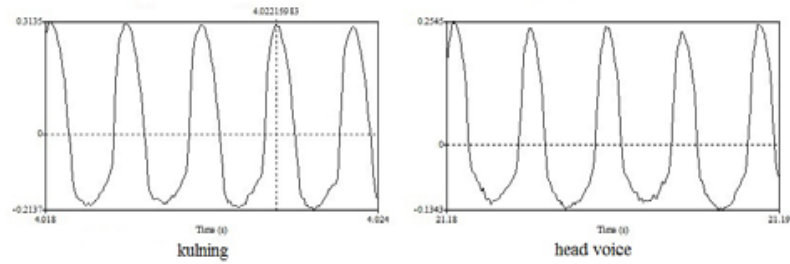

Figure 2. EGG waveform in kulning and in head register. $x$-axis $=$ time $; y$-axis $=$ vocal fold contact (increasing upwards).

\subsection{Stroboscopic and high-speed findings}

Flexible nasofiberoscopy was carried out for both head register and kulning phonations separately, and then also while the subject was performing both on just one exhalation. For the latter the subject started in head register and shifted to kulning after two seconds.

The stroboscopic recordings show clearly that several laryngeal changes took place when the subject shifted from head register to kulning. The lateral walls of the epilarynx moved more medially diminishing the width of the laryngeal inlet. The antero-posterior distance from the stem of the backside of the epiglottis to the back-wall of the laryngeal inlet also diminished. The latter change resulted in the fact that the epiglottis covered more than half of the length of the vocal folds leaving only the most posterior part of them visible. Such a limitation in visibility was also noticed in head register but to a much lesser extent due to the longer antero-posterior distance between epiglottis and the backwall of the epilaryngeal tube (arytenoid region). Additionally, the piriform fossae are more open during head register compared to kulning.

High-speed recordings were made using 4000 images per second for head register and kulning separately. Due to the short duration of the high speed recordings it was not possible to have subsequent registrations of kulning and head register in the same phonation. Comparing both high-speed videos reveal that that kulning is characterized by a marked adduction of the false vocal folds. The adduction of the vocal folds is also tighter in kulning compared to head voice.

The laryngeal data collection used both a flexible endoscope and a rigid endoscope in high speed recordings. Using a rigid endoscope requires pulling the tongue forward and applying local anesthesia to the back of the mouth to reduce gagging. According to the singer this had effects on her singing, possibly affecting vocal fold closure and thus loudness. She also felt that the forward tongue position was harder to maintain in kulning than in head register singing. However, despite these difficulties she managed to produce clear perceptual, stroboscopic, high-speed and EGG differences between kulning and head register singing.

\section{Discussion}

First, as for sound pressure level, we showed that it was higher in kulning mode than in head register mode, although the lower values were similar for both modes of singing. Kulning values peaked at around $123 \mathrm{~dB}(\mathrm{a})$ at $3 \mathrm{~cm}$ from the source, while the highest measured value for head register was $102 \mathrm{~dB}(\mathrm{a})$. As for attenuation, our previous observations that kulning voice is affected less by distance than head register were confirmed, although less markedly, with an observed difference of about $6 \mathrm{~dB}(\mathrm{a})$ at 11 meters as compared to 1 meter. While this replicated our findings that kulning mode is more resilient to distance, this difference is bigger in its natural habitat (forest) than in an indoor setting (a hospital corridor).

Higher CQ values suggest a larger contact area between the vocal folds. CQ has been found to be higher in voices with lower pitch, higher intensity, chest register or more pressed phonation compared to high pitch, low intensity and head register or hypofunctional phonation type [14]. Physiologically the results seem to suggest more adducted vocal folds with possibly higher thyroarytenoid muscle activity in kulning. The findings of the high-speed optical examination in terms of more adduction of the vocal folds come in line with the higher CQ values.

Rosenberg [19] reported that a good kulning tone is characterized by a prominent first partial and an evenly falling spectrum envelope. The spectral findings of the present study are in line with this.

Kulning compared to head voice was characterized by a less steep spectral slope. Prominence of the first partial as well as strength of the overtones may imply a non-linear source-filter interaction in terms of a better tuning of the first vocal tract resonance (formant) close to the fundamental frequency, F0 (slightly above it). Then the inertive reactance of the vocal tract will be higher at the frequency of the vocal fold vibration. That, in turn, can enhance vocal fold vibration and thus lead to strengthening of the fundamental and the overtones (see [20]). Tuning of the first formant (F1) to F0 which is as high as in the kulning samples (i.e. above $700 \mathrm{~Hz}$ ) implies raising of $F 1$. That, in turn, may be accomplished by shortening the acoustically effective vocal tract length by increasing the jaw opening, lip spreading or by raising the larynx. The inertive reactance of the vocal tract can also be raised over a wide frequency range by narrowing of the epilarynx [20], which was seen in the fiberoscopy recordings done in this study. In order to enable an effective source-filter interaction, the glottis needs to be fully closed at least $30 \%$ of the period time [21].

Further studies on kulning should address loudness (measured in sones). Physiological investigation should also consider aerodynamic parameters (subglottic pressure and airflow during phonation).

MRI registration of the vocal tract and finite-element modeling based on it would allow the calculation of vocal tract impedance. Such a study would shed further light on the origin of the high sound pressure levels obtained in kulning.

The findings of the fiberoscopic and high-speed videos are strikingly pointing to the rule of the supraglottic area in kulning. Unfortunately, no previous studies managed to get a good optical access during kulning. This can be due to the more advanced techniques we have nowadays in comparison to previous studies and also to the cooperation of the singer in this study. Although this limits the possibility of discussing our results, but it points to the importance of them in filling a missing gap in the literature.

However, our findings go in line with the findings of Titze and Story [22] and Yanagisawa [23] that the loudest qualities of singing twang, belting and opera, especially at higher 
pitches demonstrate marked narrowing of the epilarynx primarily in the anterior-posterior direction. Our findings point also to the rule of medial walls and the false vocal folds being more medial in kulning in comparison to head register.

\section{Conclusions}

SPL measurements confirmed our previous observations of a higher SPL in kulning compared to head voice. Nasoendoscopy showed a tighter constriction in the epilaryngeal inlet for kulning. High-speed imaging showed a remarkable adduction of the false vocal folds and also tighter adduction of the true vocal folds in kulning. In line with the laryngeal imaging data the EGG findings suggest a larger glottal contact area for kulning.

EGG-data and video-stroboscopy support previous findings of increased loudness in kulning compared to head register. Kulning also showed a more marked glottal closure.

Optical examination showed narrowing of the laryngeal inlet as well as more adduction of the vocal folds during kulning in comparison to head register.

\section{Acknowledgements}

Thanks to Fanny Pehrson for contributing her voice in a remarkable fashion under arduous conditions. Jaana Tyrmi is thanked for her assistance with figures. Acknowledgements are extended to Erkki Vilkman who kindly provided both equipment and facilities and without whom this work would not have been possible.

\section{References}

[1] R. Eklund, A. McAllister, F. Pehrson. 2013. An acoustic comparison of voice characteristics in 'kulning', head and modal registers. In: Robert Eklund (ed.), Proceedings of Fonetik 2013 the XXVIth Swedish Phonetics Conference, Studies in Language and Culture, no. 21, pp. 21-24.

[2] R. Eklund, A. McAllister. 2015. An acoustic analysis of 'kulning' (cattle calls) recorded in an outdoor setting on location in Dalarna (Sweden) In: Proceedings of ICPhS 2015, pp. 10-14 August 2015, Glasgow, Scotland.

[3] R. Luchsinger. Untersuchungen über die Klangfarbe der menschlichen Stimme. Archiv für Sprach- und Stimmphysiologie und Sprach- und Stimmheiligkunde, pp. 1-39, 1942.

[4] M. Echternach, B. Richter. Vocal perfection in yodelling — pitch stabilities and transition time. Logopedics Phoniatrics Vocology, vol. 35, pp. 6-12, 2010.

[5] M. Echternach, M. Marki, B. Richter. Vocal tract configurations in yodelling - prospective comparison of two Swiss yodeller and two non-yodeller subjects. Logopedics Phoniatrics Vocology, vol. 36, pp. 109-113, 2011.

[6] R.-G. Busnel, A. Classe. Whistled languages (Communication and Cybernetics 13). Berlin: Springer, 1976.

[7] S. Rosenberg. 2003. Kulning. Musiken och metoden. Stockholm: Udda Toner.

[8] C.-A. Moberg. Om vallåtar. En studie i de svenska fäbodarnas musikaliska organisation. Svensk Tidskrift för Musikforskning, pp. 1-27, 1955

[9] J. Ling. Svensk folkmusik. Stockholm: Prisma, 1978.

[10] A. Johnson. Voice Physiology and Ethno-musicology: Physiological and acoustical Studies of the Swedish Herding Song. In: D. Christensen (ed.), Yearbook for Traditional Music, vol. $16,42-66,1984$.
[11] A. Johnson. Sången i skogen: Studier kring den svenska fäbodmusiken. PhD thesis, Dept. of Musicology, Uppsala University, 1986.

[12] M.T. Uttman. Eine Untersuchung der Teiltonspektren bei Kulning und Lockruf-techniken anhand von Beispielen aus Schweden und Finnland. STM-Online, 5, 2002. http://musikforskning.se/stmonline/vol_5/tellenbach/index.php? menu $=3$

[13] H.J. Rubin, C.C. Hirt. The falsetto. A high speed cinematographic study. Laryngoscope, vol. 70, pp. 1305-1324, 1960.

[14] R.J. Baken, R.F. Orlikoff. Clinical Measurement of Speech and Voice $\left(2^{\text {nd }} e d\right)$. San Diego: Singular Thomson Learning, 2000.

[15] P. Fabre. Un procédé électrique percutané d'inscription de l'accolement glottique au cours de la phonation. Glottographie de haute fréquence. Premiers résultats. Bulletin de l'Academie Nationale de Medecine, vol. 141, pp. 66-69, 1957.

[16] M. Rothenberg, J. Mashie. Monitoring vocal fold abduction through vocal fold contact area. Journal of Speech Language and Hearing Research, vol. 31, pp. 338-351, 1988.

[17] C. Herbst, S. Ternström. A comparison of different methods to measure the EGG contact quotient. Logopedics Phoniatrics Vocology, vol. 31, pp. 26-38, 2006

[18] N. Henrich, C. d'Alessandro, B. Doval, M. Castellengo. On the use of the derivative of electroglottographic signal for characterization of nonpathological phonation. Journal of the Acoustical Society of America, vol. 115, pp. 1321-32, 2004.

[19] S. Rosenberg. Kulning - an ornamentation of the surrounding emptiness: about the unique Scandinavian herding calls. Voice and Speech Review, vol. 8, no. 1, pp. 100-105, 2014.

[20] I.R. Titze. Nonlinear source-filter coupling in phonation: Theory. Journal of the Acoustical Society of America, vol. 123 no. 5, pp. 2733-2749, 2008.

[21] M. Rothenberg, H. Schutte. Interactive Augmentation of Voice Quality and Reduction of Breath Airflow in the Soprano Voice. Journal of Voice. Available online 10 November 2015.

[22] I.R. Titze, B.H. Story. Acoustic interactions of the voice source with the lower vocal tract. Journal of the Acoustical Society America, vol. 101, pp. 2234-2243, 1997

[23] E. Yanagisawa, J. Estill, T. Kmucha, S.B. Leder. The contribution of aryepiglottic constriction to "ringing" voice quality - a videolaryngoscopic study with acoustic analysis. Journal of Voice, vol. 3, pp. 342-350, 1989. 